Aim of the study: The existence of a correlation between allergy disorders and cancer diseases has been confirmed by several epidemiological studies. Although the molecular mechanism involved in this phenomenon remains unknown, there are data indicating that certain cytokines, engaged in allergic processes, have antineoplastic activities. The aim of the present study was to explore the association between advanced breast cancer and allergic state on the molecular level. Material and methods: We determined and compared the mRNA and protein expression of interleukin-1 $\beta$ (IL-1 $\beta$ ), IL-4, IL-6, and interferon- $\gamma$ (IFN- $\gamma$ ), cytokines known for antitumor properties, in the blood of advanced breast cancer patients and individuals with allergic diseases related to type 2 response. In addition, we performed an in vitro assay of reactivity of peripheral blood mononuclear cells after exogenous antigen stimulation. As a preliminary to molecular analysis we conducted a questionnaire study concerning the incidence of allergy among breast cancer patients and healthy subjects without malignancy.

Results: The results of the survey study revealed a negative relation between breast cancer and allergy prevalence. Subsequent molecular analysis, however, did not show statistically significant differences in cytokines mRNA and protein expression levels between allergic patients and those with malignancy. The in vitro reactivity test also did not reveal marked differences between IL-1 $\beta$, IL-4 and IL- 6 production after PBMC triggering with exogenous antigen. Conclusions: We concluded that the studied cytokines (IL-1 $\beta$, IL-4, IL-6, and IFN- $\gamma$ ) are not engaged in breast cancer-allergy negative relation.

Key words: breast cancer, allergy, peripheral blood mononuclear cells, cytokines, mRNA expression.

Contemp Oncol (Pozn) 2014; 18 (6): 396-402 DOI: $10.5114 /$ wo.2014.47903

\section{Analysis of the involvement of cytokines in allergy and breast cancer association}

\author{
Małgorzata E. Kowalczewska ${ }^{1}$, Anna Brożyna², Wojciech Jóźwicki², \\ Krzysztof Pławski ${ }^{3}$, Michał Przybyszewski ${ }^{4}$, Sylwia Wrotek ${ }^{1}$, \\ Zbigniew Bartuzi ${ }^{4}$, Wiesław Kozak ${ }^{1}$
}

${ }^{1}$ Department of Immunology Faculty of Biology and Environment Protection Nicolaus Copernicus University, Torun, Poland

2Department of Tumor Pathology and Pathomorphology, Oncology Center Prof. Franciszek Łukaszczyk Memorial Hospital, The Ludwik Rydygier Collegium Medicum of Nicolaus Copernicus University, Bydgoszcz, Poland ${ }^{3}$ Department of Breast Cancer and Reconstructive Surgery, Oncology Center Prof. Franciszek Łukaszczyk Memorial Hospital, Bydgoszcz, Poland ${ }^{4}$ Department of Allergology, Clinical Immunology and Internal Medicine, The Ludwik Rydygier Collegium Medicum of Nicolaus Copernicus University, Bydgoszcz, Poland

\section{Introduction}

The debate concerning the relation between allergy and cancer is not recent. In the 1970 s researchers suggested that allergy, defined as a hypersensitivity state of the immunological system, may reduce the occurrence of cancer $[1,2]$. Their reports became the starting point for discussion about the nature of the relation between allergy and neoplastic disease. The considerable increase in allergy cases in recent decades in combination with cancer immunology development have enhanced the interest in such a relationship [3]. An association between allergic disorders and cancer risk is supported by epidemiological studies; however, the exact nature of this relation remains unclear $[4,5]$. The inverse association has been reported for leukaemia [6, 7], glioma [8-10], and pancreatic cancer [11, 12] while a history of asthma has been positively correlated with lung cancer [13-15]. In the case of breast cancer the nature of the relation with allergies remains controversial. Results of epidemiological studies have provided support for two opposed hypotheses. Studies reporting a protective effect of allergy support the thesis, in accordance with "enhanced immunological surveillance theory" [16], that the stimulated immune system is able to detect and eliminate malignant tumour cells more effectively, before they become clinically manifest [17, 18]. In contrast, studies reporting allergy to be associated with an increased risk of cancer support the theory that the alterations of the immunological system can enhance the inflammatory response and favour tumour transformation through mechanisms of repeated tissue repair that result in random pro-oncogenic mutations in actively dividing stem cells $[3,5]$.

Previously our laboratory conduced a wide-range study concerning a history of fever in cancer patients during the infection processes. The information about a history of allergy was also obtained. The results revealed that the incidence of allergy was noticeably decreased among cancer patients compared to healthy volunteers (5.92\% and 22.13\%, respectively) [19]. These data turned our interest to the nature of the relation between advanced breast cancer - the most common form of malignancy and the primary cause of death due to neoplasms among European females [20] - and allergic diseases related to type 2 response.

Since the exact molecular mechanism involved in the relationship between allergic condition and cancer is still unknown, the aim of our study was to investigate whether there are differences between allergic individuals and breast cancer patients, in the blood level of specific molecular messengers, which 
might be responsible for triggering cancer prevention actions. We decided to explore this association by determining the mRNA and protein expression of selected cytokines - interleukin-1 $\beta$ (IL-1 $\beta)$, IL-4, IL-6, and interferon- $\gamma$ (IFN- $\gamma)$ - known for their antitumor properties, in the blood constituents of advanced breast cancer patients and allergic individuals. In addition, we compared the in vitro reactivity of the peripheral blood mononuclear cells (PBMC) isolated from women with allergies and those with cancer disease. The reactivity level was measured by cytokine release (IL-1 $\beta$, IL-4, and IL-6) following stimulation of the cells with exogenous antigen.

\section{Material and methods}

\section{Questionnaire study}

Due to inconsistent results of prospective studies [4, 21, 22] we conducted an additional questionnaire study concerning the incidence of allergy among breast cancer female patients and healthy volunteers (without malignancy). Information on the prevalence of allergic rhinitis, allergic contact dermatitis, hymenoptera venom allergy, and food allergy was obtained.

The survey study was conducted during a relatively short period, from February 2010 to May 2011. Retrospective information on the incidence of self-reported allergy was obtained from 403 patients with breast cancer and 155 healthy volunteers, by use of a questionnaire, and from 226 breast cancer patients through medical history (during visits to oncology clinics).

Breast cancer respondents were patients of the Clinical Department of Breast Cancer and Reconstructive Surgery, Oncology Center - Prof Łukaszczyk Memorial Hospital in Bydgoszcz (Poland). Each breast cancer patient had documented tissue diagnosis of cancer from pathology records. The majority of the examined patients were from the Kujawsko-Pomorskie voivodeship of Poland, and the healthy control volunteers were randomly selected from the same area. The responded cohort consisted of 784 women. The average age was 58 (ranging from 37-84 years old) and 51 (ranging from 31-72 years old) years for breast cancer patients and healthy (without cancer) volunteers, respectively. Informed written consent for participation in the study and subsequent use of data was obtained from participants at the time of the survey. Only completely filled out questionnaire forms were analysed. The $\chi^{2}$ test was used to compare rates of allergy occurrence between patients with breast cancer and healthy people.

\section{Molecular study}

\section{Donors (subjects)}

Samples of venous blood were obtained from eighteen female patients with an average age of 50 years. Advanced breast cancer patients with documented tissue diagnosis of cancer were from the Oncology Center of Prof Łukaszczyk Memorial Hospital in Bydgoszcz (Poland). Females with allergic diseases related to type 2 response (Table 1) were patients of University Hospital No. 2, Department of Allergology, Clinical Immunology, and Internal Medicine in Bydgoszcz (Poland). The presence of allergy lgE antibodies was confirmed by an allergy skin-prick test. The control blood was obtained from
Table 1. Criteria for determination of allergy

\begin{tabular}{ll}
$\begin{array}{l}\text { Type of } \\
\text { allergy }\end{array}$ & $\begin{array}{l}\text { Allergic disease related to type } 2 \text { response: } \\
\text { allergic rhinitis } \\
\text { allergic contact dermatitis } \\
\text { food allergy }\end{array}$ \\
$\begin{array}{l}\text { Positive } \\
\text { allergy }\end{array}$ & Presence of allergy IgE antibodies \\
\hline
\end{tabular}

healthy volunteers of the same age. All subjects gave written informed consent. The Ethical Committee at the Ludwik Rydygier Collegium Medicum, Nicolaus Copernicus University approval for experiment was received.

\section{mRNA expression analysis}

Mononuclear cell purification. Cells were separated from $5 \mathrm{ml}$ of venous blood using density gradient centrifugation method [23] with use of LSM 1077 Lymphocyte Separation Medium (PAA, The Cell Culture Company, Austria).

RNA isolation. Total RNA isolation was performed according to the Chomczynsky method [24] by using TRI® Reagent (Sigma ${ }^{\circledR}$, USA). The RNA sample concentration was measured by Nanodrop ${ }^{\circledR}$ ND - 1000 Spectrophotometer (Thermo scientific, USA).

MRNA expression analysis by PCR. The first strand of complementary DNA (CDNA) was generated from 1 ug RNA by using SuperScript ${ }^{\mathrm{TM}}$ \|l Reverse Transcriptase (Invitrogen ${ }^{\mathrm{TM}}$, USA). Gene-specific cDNA amplification ( $\beta$-actin, IL-1 $\beta$, IL-4, IL-6, IFN- $\gamma$ ) was performed by using Taq DNA Polymerase (Invitrogen ${ }^{\mathrm{TM}}$, Brazil). The reaction product was visualized on a $1 \%$ agarose gel containing ethidium bromide $(\sim 1 \mu \mathrm{g} / \mathrm{ml})$. Primers used (designed by the authors using the GenBank NCBI database and the following programs: Oligo Analyzer 3.1, Clustal W, and Primer Blast) were as follows (forward/ reverse):

$\beta$-actin (287bp): 5'-TGGGCATGGGTCAGAAGGATTC-3'

5'-TAGCACAGCCTGGATAGCAACG-3';

IL-1 $\beta$ (195 bp): 5'-GACTTCACCATGCAATTTGT-

GTCTTCCTAA-3',

5'-ACAGGAGATCCTCTTAGCACTACCCTAAG-3';

IL-4 (239 bp): 5'-CGTAACAGACATCTTTGCTGCC-3'

5'-TACTCTGGTTGGCTTCCTTCAC-3';

IL-6 (120 bp): 5'-GCTGCAGGACATGACAACTCATCTCATTC-3'

5'-ATGCCCATTAACAACAACAATCTGAGGTG-3'

IFN- $\gamma$ (386 bp): 5'-AGAGCATCCCAGTAATGGTTGTCCTG-3', 5'-TTTCAAACCGGCAGTAACTGGATAGTATCA-3'.

mRNA cytokine expression quantification. The quantification of cytokine mRNA level expression was done using UN-SCAN-IT gel 6.1 (USA). Following ethidium bromide staining, the intensity of the DNA fragments was densitometrically scanned using UN-SCAN-IT gel 6.1.

\section{Cytokine level analysis}

Six $\mathrm{ml}$ of blood were collected into serum separator tubes and allowed to clot for 30 minutes at $23^{\circ} \mathrm{C}$ before centrifugation for 15 minutes at $1000 \times$ g. Serum level of IL-1 $\beta$, IL-4, IL-6, and IFN- $\gamma$ was assessed by ELISA assay using a Synergy HT Multi-Mode Microplate Reader (BioTek; USA), according to the manufacturer's instructions (R\&D Systems, USA). 
Table 2. Incidence of allergic disease among breast cancer patients and control group

\begin{tabular}{|lcc|}
\hline Type of allergy & $\begin{array}{c}\text { Breast cancer } \\
\text { patients } \\
(n=629)\end{array}$ & $\begin{array}{c}\text { Control group } \\
(n=155)\end{array}$ \\
\hline Allergic rhinitis & 22 & 28 \\
\hline Allergic contact dermatitis & 25 & 24 \\
\hline Hymenoptera venom allergy & - & 5 \\
\hline Food allergy & 11 & 4 \\
\hline Total & 58 & 61 \\
\hline Rate of allergy disease $(\%)$ & 9.22 & 39.5 \\
\hline
\end{tabular}

\section{Cell reactivity analysis}

Peripheral blood mononuclear cells were isolated from venous blood by density gradient centrifugation method. Isolated cells $\left(2 \times 10^{6}\right)$ were transferred to 6-well cell culture plates and suspended in $2 \mathrm{ml}$ of standard cell culture medium (RPMI-1640 with L-glutamine; Sigma Aldrich; Germany) supplemented with 10\% heat-inactivated foetal bovine serum (FBS, PAA; Austria). Culture plates were placed at $37^{\circ} \mathrm{C}$ in an incubator providing a humidified atmosphere containing 5\% $\mathrm{CO}_{2}$ for 1 hour. After preincubation the cells were stimulated with lipopolysaccharide (LPS) form E. coli (Sigma Aldrich; Germany) in a concentration of $1 \mu \mathrm{g} / \mathrm{ml} / 10^{6}$ cells. As a control, cells were incubated with $0.9 \% \mathrm{NaCl}$. After four hours of incubation, cell suspensions were collected and transferred into sterile $2-\mathrm{ml}$ microcentrifuge tubes. Samples were centrifuged for 10 minutes at $1500 \times \mathrm{g}$ and $23^{\circ} \mathrm{C}$. Supernatants were collected and stored at $-40^{\circ} \mathrm{C}$ until analysed. The cell supernatants were assayed for the presence of IL-1 $\beta$, IL-4, and IL-6 using ELISA technique (R\&D Systems, USA).

\section{Statistical analyses}

All values are reported as means \pm standard error means (S.E.M.) and were analysed by analysis of variance (ANOVA) followed by Student's t-test with the level of significance set at $p<0.05$. Statistical analyses were performed with use of GraphPad Prism 6 (USA).

\section{Results}

The results of our questionnaire study have shown that $39.35 \%$ of healthy volunteers reported a history of allergy; whereas only $9.22 \%$ of all advanced breast cancer patients had previous allergic disorders (Table 2 ).

\section{IL-1 $\beta$ mRNA and protein expression}

The PCR analysis demonstrated that the transcription level of the interleukin-1 $\beta$ (IL-1 $1 \beta$ ) gene was higher in mononuclear cells isolated from the blood of the allergic patients and control group compared to breast cancer patients (Fig. 1, $2 A)$. These differences in IL- $\beta$ mRNA between the cancer group and the two other groups were significant $(p<0.01)$. In contrast to mRNA level measurement, the results of ELISA tests specifically directed against IL-1 $1 \beta$ showed no differences in the concentration of this cytokine between the sera collected from patients with breast cancer, those with allergy, and the control individuals (Fig. 2B).

\section{IL-4 mRNA and protein expression}

In the case of IL-4, a trend towards increased mRNA in PBMC of breast cancer patients was detected (Fig. 3A). Differences between this group and allergic individuals, as well as controls, were statistical significant $(p<0.001$, $p<0.01$, respectively). The serum concentrations of IL-4 however, did not differ between any of the groups (Fig. 3B).

\section{IL- 6 and IFN- $\gamma$ mRNA and protein expression}

The mRNA expression of IL- 6 and IFN- $\gamma$ did not differ between allergy and cancer patients (Fig. 4A and 5A, respectively).

The protein concentration of IL-6 was increased in the serum of allergic patients in comparison to cancer patients and healthy controls. However, despite statistically significant differences between the groups (Fig. 4B), the level of this interleukin was on the borderline of the ELISA test $(\sim 3.12 \mathrm{pg} / \mathrm{ml})$.

Elevated protein level of IFN- $\gamma$ in the serum of allergic and cancer patients compared to controls was observed. However, because of the substantial individual differences in the IFN- $\gamma$ expression within the group of patients with cancer, as well as those with allergy, there was no statistically significant difference between these clusters of patients (Fig. 5B).

\section{Cell reactivity analysis following stimulation with LPS}

Stimulation of PBMC with LPS significantly increased the production of IL-1 $\beta$, IL-4, and IL-6 compared to those incu-

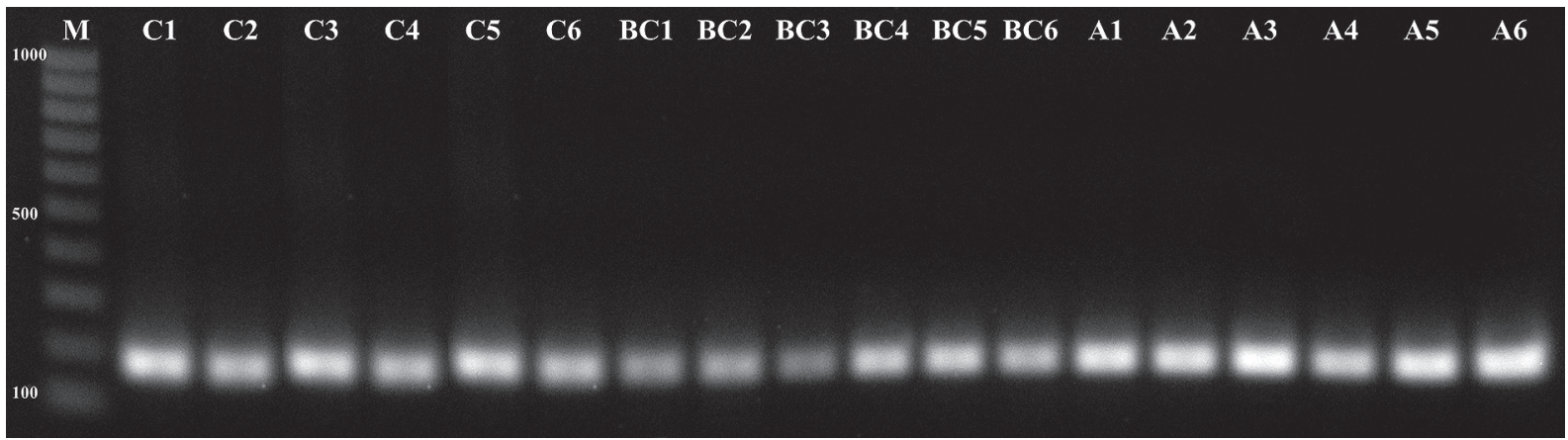

Fig. 1. Gel electrophoresis of IL-1 $\beta$ mRNA expression among control individuals $(n=6)$, cancer patients $(n=6)$, and allergic patients $(n=6)$. Line 1: M: 100-1000 bp marker (Sigma), Line 2-7: samples derived from controls (C1-C6). Line 8-13: samples from breast cancer patients (BC1-BC6), Line 13-18: samples from allergic patients (A1-A6) 

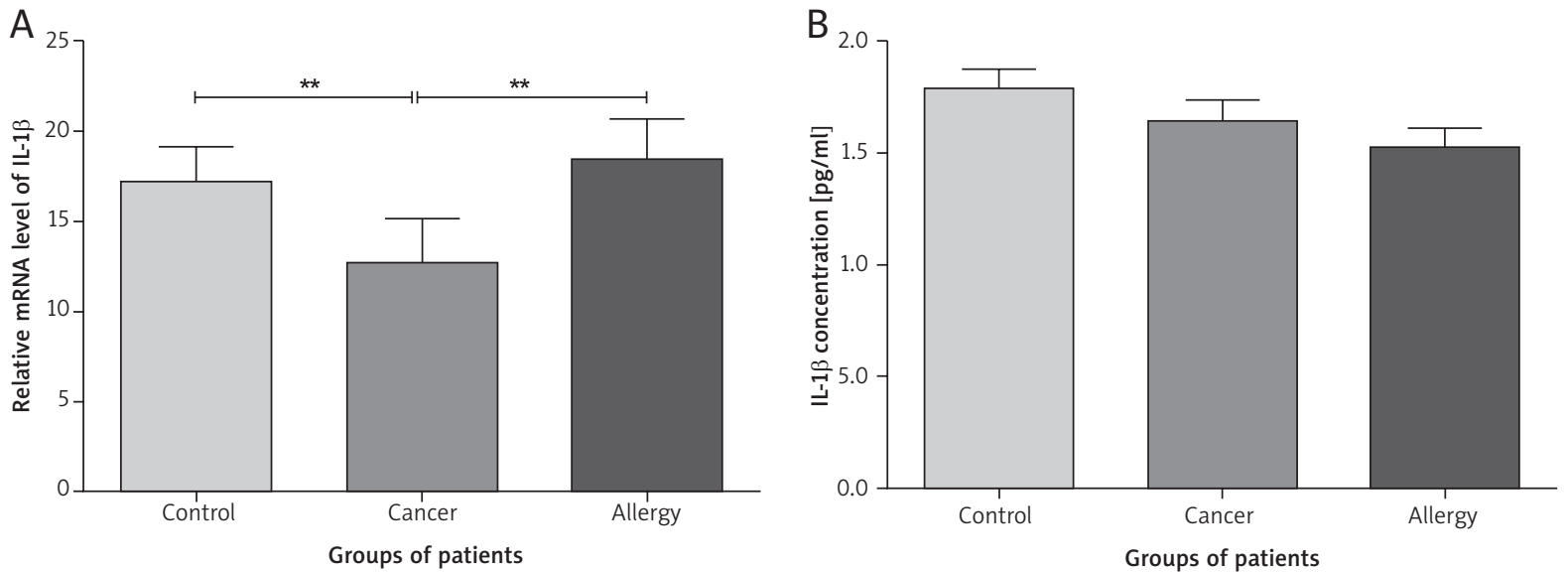

Fig. 2. A) Relative level of IL-1 $\beta$ mRNA expression among control individuals $(n=6)$, cancer patients $(n=6)$, and allergic patients $(n=6)$. Densitometry gel analysis with UN-SCAN-IT 6.1. B) Concentration of IL-1 $\beta$ in serum of control individuals $(n=6)$, breast cancer patients $(n=6)$, and allergic patients $(n=6)$. All values are expressed as means \pm S.E.M. of all samples within the groups. Asterisk indicates significant difference between groups $\left(^{* *} p<0.01\right.$, Student's $t$-test)
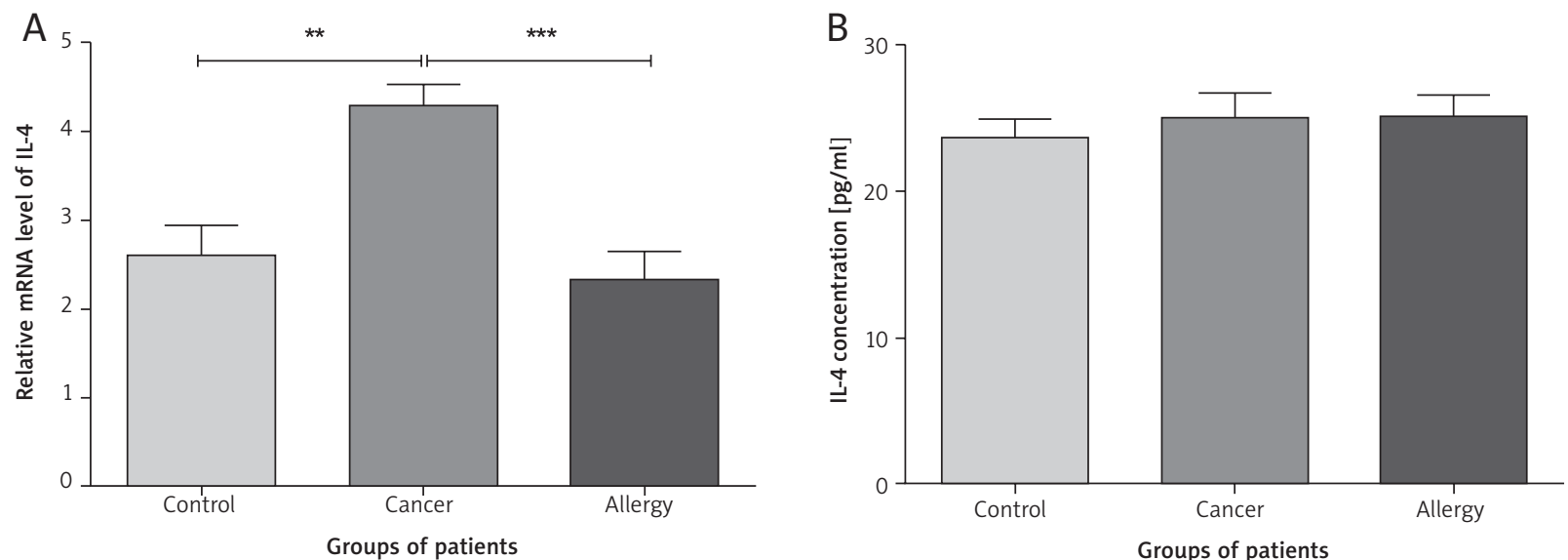

Fig. 3. A) Relative level of IL-4 mRNA expression among control individuals $(n=6)$, cancer patients $(n=6)$ and allergic patients $(n=6)$. Densitometry gel analysis with UN-SCAN-IT 6.1. B) Concentration of IL-4 in serum of control individuals $(n=6)$, breast cancer patients $(n=6)$, and allergic patients $(n=6)$. All values are expressed as means \pm S.E.M. of all samples within the groups. Asterisk indicates significant difference between groups $\left({ }^{* *} p<0.01,{ }^{* * *} p<0.001\right.$, Student's $t$-test)
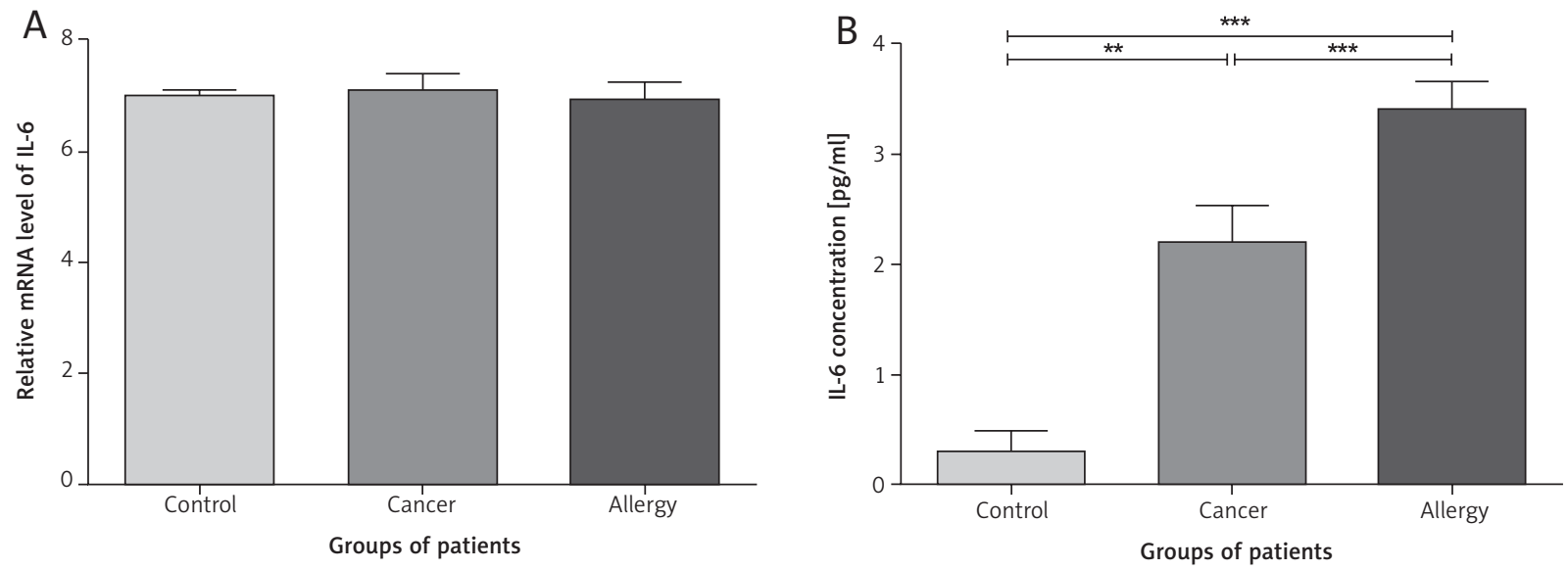

Fig. 4. A) Relative level of IL-6 mRNA expression among control individuals $(n=6)$, cancer patients $(n=6)$, and allergic patients $(n=6)$. Densitometry gel analysis with UN-SCAN-IT 6.1. B) Concentration of IL-6 in serum of control individuals $(n=6)$, breast cancer patients $(n=6)$, and allergic patients $(n=6)$. Values are expressed as means \pm S.E.M. of all samples within the groups. Asterisk indicates significant difference between groups $\left({ }^{* *} p<0.01,{ }^{* * *} p<0.001\right.$, Student's $t$-test) 

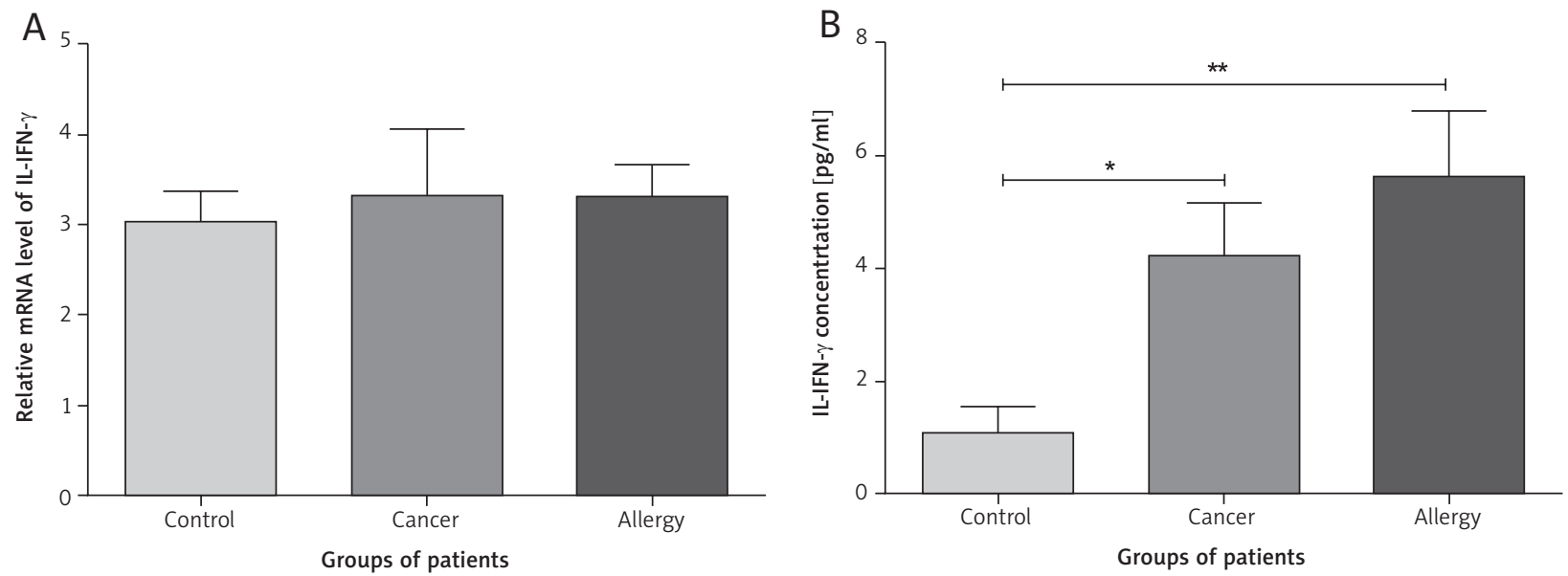

Fig. 5. A) Relative level of IFN- $\gamma$ mRNA expression among control individuals $(n=6)$, cancer patients $(n=6)$, and allergic patients $(n=6)$. Densitometry gel analysis with UN-SCAN-IT 6.1. B) Concentration of IFN- $\gamma$ in serum of control individuals $(n=6)$, breast cancer patients $(n=6)$, and allergic patients $(n=6)$. All values are expressed as means \pm S.E.M. of all samples within the groups. Asterisk indicates significant difference between groups $\left({ }^{*} p<0.05\right.$, Student's $t$-test)

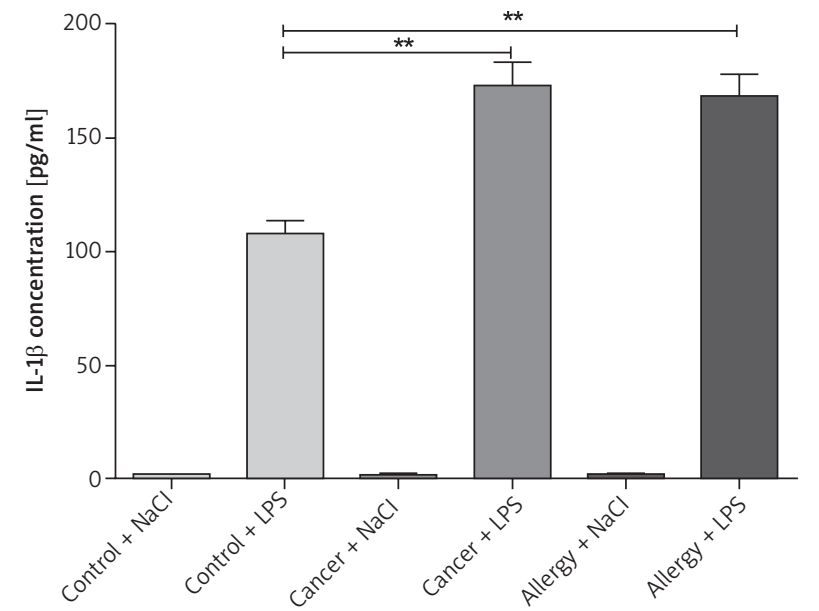

Fig. 6. Changes in IL-1 $\beta$ concentration after PBMC in vitro LPS stimulation (abbreviations: control - healthy individuals, $n=3$; cancer - breast cancer patients, $n=3$; allergy - Th2 allergic individuals, $n=3)$. Values are expressed as means \pm S.E.M. of all samples within the groups. Asterisk indicates significant difference between groups ${ }^{* *} p<0.01$, Student's $t$-test)

bated with $\mathrm{NaCl}$ as a control (Fig. 6, 7, 8). In addition, we observed a marked increase in IL-1 $\beta$, IL-4, and IL- 6 production after LPS stimulation of PBMC isolated from the blood of neoplastic and allergic patients compared to healthy controls. However there were no significant differences in supernatant levels of these cytokines between breast cancer and allergic samples in response to the exogenous antigen.

\section{Discussion}

There have been relatively few prospective studies concerning the association between allergic disorders and breast cancer disease. Three studies previously demonstrated non-significant increased risk of breast cancer among women who reported a history of allergy [4, 25, 26]. In contrast, the results of a population-based case-control study conducted in the United States (western Washington) has shown that a history of allergies was associat-

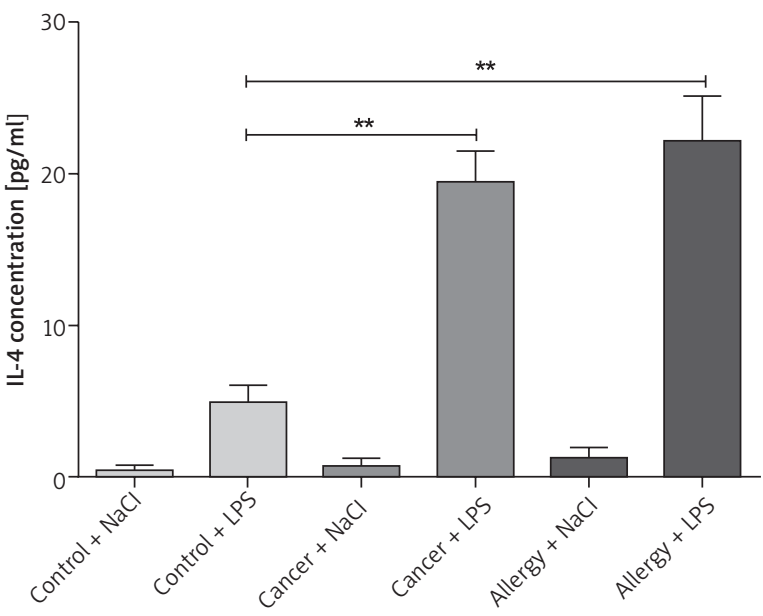

Fig. 7. Changes in IL-4 concentration after PBMC in vitro LPS stimulation (abbreviations: control - healthy individuals, $n=3$; cancer - breast cancer patients, $n=3$; allergy - Th2 allergic individuals, $n=3)$. Values are expressed as means \pm S.E.M. of all samples within the groups. Asterisk indicates significant difference between groups $\left({ }^{* *} p<0.01\right.$, Student's $t$-test)

ed with a reduced risk of breast cancer for women older than 35, but not for women 35 years old or younger [27]. Similar to these findings, a large case-control study among women in Ontario (Canada) carried out during 2002-2003 found that a history of allergies or hay fever may be associated with a small reduction in breast cancer risk [22]. Conversely, a prospective study of the Busselton cohort found no correlation between allergy and breast cancer among female members of the cohort [16]. Recently, Vojtechova and Martin [21] concluded that there is little epidemiological support for the immune surveillance theory or antigen stimulation theory in breast carcinogenesis.

Our additional questionnaire study revealed a significant decrease in the incidence of allergies among breast cancer patients compared to healthy subjects, without malignancy. A more than 4-fold lower frequency of allergy among patients with breast cancer compared to women without malignancy $\left(\chi^{2}=24.67, p<0.0001\right)$ has provided the basis for 
the hypothesis of a negative relation between breast cancer and hypersensivity state to allergens. This theory is consistent with previous reports showing reduced reactivity of the immune system in patients with neoplastic disease [1, 28], whereas in allergic individuals excessive stimulation of the immune system by the allergen improves the tumour cell detection and elimination abilities [25, 29].

In order to investigate whether allergy has the preventative ability against tumour development we conducted a molecular analysis with the aim of estimating and comparing the mRNA and protein levels of selected cytokines suspected to be involved in this process, in the blood of allergic and breast cancer patients. Moreover, we performed additional analysis to investigate the reactivity of PBMC derived from patients with breast cancer and those with allergy. We assumed that cell response following in vitro antigen stimulation might be elevated in the culture of cells isolated from the blood of hypersensitive subjects compared to women with breast malignancy. We focused on cytokines because, as has been proven in numerous experimental and clinical studies, they significantly affect tumour growth in vivo. Due to the fact that these factors are produced by different cells (immunocompetent and diseased ones), they represent a network with a variety of molecularly and functionally different molecules. They may act either as tumour growth promoting or inhibiting factors [30].

Numerous studies indicate that a host's immune response to infection and allergy may play a role in the process of cancer cell destruction. It is possible that IL-1 $1 \beta$, which was originally identified as an endogenous pyrogen, participates in this process. Being a factor that activates lymphocytes, IL-1 $\beta$ enhances B cell activation, leading, among other activities, to immunoglobulin $\mathrm{E}$ ( $\mathrm{gE}$ ) production [31]. Humprey and White [32] showed that IgE antibodies play a role in antigen-antibody reaction, which results in elimination of cancer cell clones. IgE, in addition to other activities, stimulate the production, by eosinophils and macrophages, of reactive oxygen metabolites and nitric oxide, which play crucial roles in tumour eradication [33]. Systemic IL-1 $\beta$, being an activator of IgE production, seems to exert a protective antitumor activity. The higher mRNA level of this cytokine in the blood of patients with allergies compared to breast cancer patients (Fig. 1, 2A) forms the basis from which to consider this molecule as part of a molecular mechanism engaged in the inverse association between breast cancer and allergy. However, due to the results of ELISA tests (protein level and PBMC reactivity), further research involving larger numbers of patients is required, to verify the possible role of IL-1 $\beta$ in the examined relation.

Owing to the fact that, IL-4 is considered as an inhibiting growth factor of cancer cells, we decided to investigate its potential role in breast cancer-Th2-related allergy negative relationship. Several lines of evidence suggest that IL-4, produced mainly by Th2 lymphocytes, could display antitumor activity. IL-4 suppresses cancer development through stimulation of B cell differentiation and IgE synthesis, as well as proliferation of antigen-specific cytotoxic $T$ lymphocytes [34]. Tepper et al. [35] suggested that the anti-tumour effect of IL-4 might be also mediated by an inflammatory infiltrate

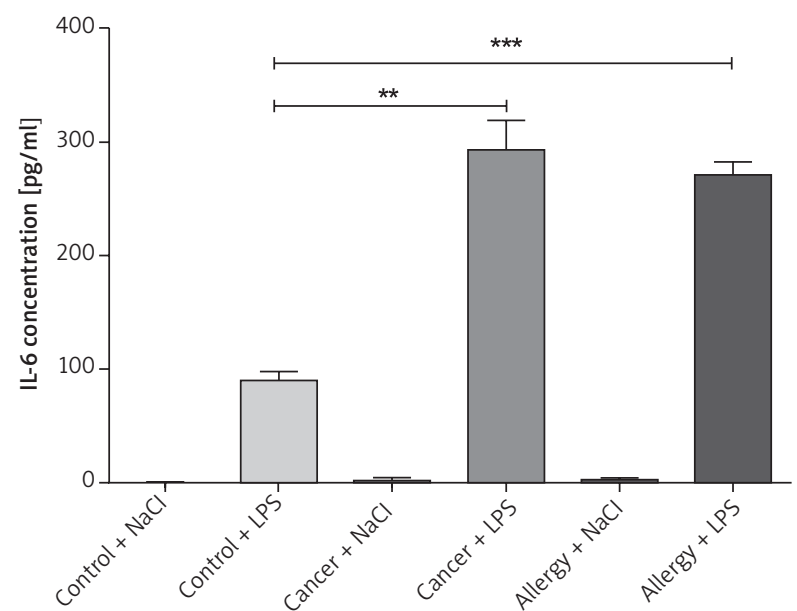

Fig. 8. Changes in IL- 6 concentration after PBMC in vitro LPS stimulation (abbreviations: control - healthy individuals, $n=3$; cancer - breast cancer patients, $n=3$; allergy - Th2 allergic individuals, $n=3)$. Values are expressed as means \pm S.E.M. of all samples within the groups. Asterisk indicates significant difference between groups ${ }^{* *} p<0.01,{ }^{* * *} p<0.001$, Student's $t$-test)

composed of eosinophils and macrophages. The results of an in vitro study performed by Toi et al. [36] showed that IL-4 inhibited the growth of breast carcinoma cells, including the hormone-dependent ones. Gooch et al. [37] demonstrated in turn that in vitro IL-4 treatment resulted in growth inhibition and induction of apoptosis in human breast cancer cells in a STAT6-dependent manner.

Our results, contrary to expectations, showed a significant decrease of mRNA expression of this cytokine in the blood of allergic patients compared to breast cancer individuals (Fig. 3A). Serum concentrations of IL-4 and production of this molecule by the cells triggered with LPS did not show any differences between the groups of patients (Fig. 3B, 7). To clarify whether cytokines with antitumor properties may be involved in breast cancer-allergy inverse association we performed subsequent analysis of IL-6 and IFN- $\gamma$ expression. In vitro studies revealed that IL- 6 has a potential to inhibit breast cancer cell development, while IFN- $\gamma$ possesses antiproliferative and antiangiogenic activities $[38,39]$. Our results of IL-6 mRNA expression measurement did not show any differences between the groups (Fig. 4A). Serum concentrations of this cytokine were higher in allergic patients compared to breast cancer and healthy subjects (Fig. 4B); however, all results were on the threshold of the method's sensitivity. Moreover, the reactivity of cells measured by IL-6 production did not differ between the examined groups (Fig. 8). In the case of IFN- $\gamma$ we did not note significant differences between groups of patients in relative mRNA levels (Fig. 5A). However, the protein measurement revealed higher concentrations of this cytokine in allergic individuals (Fig. 5B), suggesting its possible role in cancer prevention processes.

Considering the results, we postulate that the studied cytokines (IL-1 $\beta$, IL-4, II-6, and IFN- $\gamma$ ) are not involved in the negative relation between breast cancer and allergy reported in the questionnaire study. However, because of the prelimi- 
nary character of our study, analyses among larger groups of patients are needed to better characterise this association.

In conclusion, further immunological investigations concerning the evaluation of the differences in cytokines, as well as blood immunocompetent cell profiles between breast cancer patients and allergic individuals, are needed in order to explore the molecular mechanism engaged in the postulated negative association.

The authors declare no conflict of interests.

This study was supported by the scholarship: 'Step to the future - the scholarships for PhD students $3^{\text {rd }}$ edition' co-financed by the European Union within the European Social Fund, Polish budget and the Marshal's Office of the Kujawsko-Pomorskie Voivodeship (agreement number: SP III 4345-1-97-3040-614/10) and Nicolaus Copernicus Intramural Grant 540-B to M. Kowalczewska.

\section{References}

1. Mackay WD. The incidence of allergic disorders and cancer. $\mathrm{Br}$ J Cancer 1966; 20: 434-7.

2. Shapiro S. Allergy and cancer. Lancet 1973; 1: 1055.

3. Carrozzi L, Viegi G. Allergy and cancer: a biological and epidemiological rebus. Allergy 2005; 60: 1095-97.

4. Chae YK, Neagu S, Kim J, Smyrlis A, Gooptu M, Tester W. Association between Common Allergic Symptoms and Cancer in the NHANES III Female Cohort. Plos One 2012; 7: 1-7.

5. Josephs DH, Spicer JF, Corrigan CJ, Gould HJ, Karagiannis SN. Epidemiological associations of allergy, IgE and cancer. Clin Exp Allergy 2013; 43: 1110-23.

6. Schuz J, Morgan G, Böhler E, Kaatsch P, Michaelis J. Atopic disease and childhood acute lymphoblastic leukemia. Int J Cancer 2003; 105: 255-60.

7. Lariou ML, Dikalioti SK, Dessypris N, et al. Allergy and risk of acute lymphoblastic leukemia among children: A nationwide case control study in Greece. Cancer Epidemiology 2013; 37: 146-51.

8. Wiemels JL, Wiencke JK, Sison JD, Miike R, McMillan A, Wrensch M. History of allergies among adults with glioma and controls. Int J Cancer 2002; 98: 609-15.

9. Chen C, Xu T, Chen J, Zhou J, Yan Y, Lu Y, Wu S. Allergy and risk of glioma: a meta-analysis. Eur J Neurol 2011; 18: 387-95.

10. Zhao H, Cai W, Shitao S, Zhi D, Lu J, Liu S. Allergic conditions reduce the risk of glioma: a meta-analysis based on 128,936 subjects. Tumor Biol; 2014: 35: 3875-80.

11. Gandini S, Lowenfels AB, Jaffee EM, Armstrong TD, Maisonneuve P. Allergies and the risk of pancreatic cancer: a meta-analysis with review of epidemiology and biological mechanisms. Cancer Epidemiol Biomarkers Prev 2005; 14: 1908-16.

12. Cotterchio M, Lowcock E, Hudson TJ, Greenwood C, Gallinger S. Association between allergies and risk of pancreatic cancer. Cancer Epidemiol Biomarkers Prev 2014; 23: 469-80.

13. Boffetta P, Ye W, Boman G, Nyrén O. Lung cancer risk in population-based cohort of patients hospitalized for asthma in Sweden. Eur Respir J 2002; 19: 127-33.

14. Turner MC, Chen Y, Krewski D, Ghadirian P, Thun MJ, Calle EE. Cancer mortality among US men and women with asthma and hay fever. Am J Epidemiol 2005; 162: 212-21.

15. Rosenberger A, Bickeböller H, McCormack V, et al. Asthma and lung cancer risk: a systematic investigation by the International Lung Cancer Consortium. Carcinogenesis 2012; 33: 587-97.

16. Talbot-Smith A, Fritschi L, Divitini ML, Mallon DF, Knuiman MW. Allergy, atopy, and cancer: a prospective study of the 1981 Busselton cohort. Am J Epidemiol 2003; 157: 606-12.

17. Prizment AE, Folsom AR, Cerhan JR, Flood A, Ross JA, Anderson KE. History of allergy and reduced incidence of colorectal cancer, lowa
Women's Health Study. Cancer Epidemiol Biomarkers Prev 2007; 16: 2357-62

18. Turner MC. Epidemiology: allergy history, IgE, and cancer. Cancer Immunol Immunother 2012; 61: 1493-510.

19. Wrotek S, Kamecki K, Kwiatkowski S, Kozak W. Cancer patients report a history of fewer fevers during infections than healthy controls. JPCCR 2009; 3: 1-10.

20. Abdulrahman GO, Rahman GA. Epidemiology of breast cancer in Europe and Africa. J Cancer Epidemiol 2012; 2012:915610..

21. Vojtechova P, Martin RM. The association of atopic diseases with breast, prostate, and colorectal cancers: a meta-analysis. Cancer Causes Control 2009; 20: 1091-105.

22. Lowcock EC, Cotterchio M, Ahmad N. Association between allergies, asthma, and breast cancer risk among women in Ontario, Canada. Cancer Causes Control 2013; 24: 1053-56.

23. Kozak W, Chęsy G, Lachowski A, Łączkowska V, Perlik C, Solińska T. Separation of mononuclear and granulocytic leukocyte fractions from bovine peripheral blood. The Bulletin of the Veterinary Institute in Pulawy 1983; 26: 55-60.

24. Chomczynski P, Sacchi N. Single-step method of RNA isolation by acid guanidinium thiocyanate-phenol-chloroform extraction. Anal Biochem 1987; 162: 156-9.

25. McWhorter WP. Allergy and risk of cancer. A Prospective Study Using NHANESI Follow up Data. Cancer 1988; 62: 451-5.

26. Mills PK, Beeson WL, Fraser GE, Philips RL. Allergy and cancer: organ site-specific results from the Adventist Health Study. Am J Epidemiol 1992; 136: 287-95

27. Hedderson MM, Malone KE, Daling JR, White E. Allergy and risk of breast cancer among young women (United States). Cancer Causes Control 2003; 14: 619-26.

28. Mapara MY, Sykes M. Tolerance and cancer: mechanisms of tumor evasion and strategies for breaking tolerance. Jpn J Clin Oncol 2004; 22: 1136-51.

29. Lindelöf B, Granath F, Tengvall-Linder M, Ekbom A. Allergy and cancer. Allergy 2005; 60: 1116-20.

30. Nicolini A, Carpi A, Rossi G. Cytokines in breast cancer. Cytokine Growth Factor Rev 2006; 17: 325-37

31. Nambu A. Nakae S. IL-1 and allergy. Allergol Int 2010; 59: 125-35.

32. Humphrey JH, White RG. Immunology for student of medicine. Blackwell, Oxford 1964.

33. Ockert D, Schmitz M, Hampl M, Rieber PE. Advanced in cancer immunotherapy. Immunol Today 1999; 20: 63-5.

34. Defrance T, Fluckiger AC, Rossi JF, Magaud JP, Sotto JJ, Banchere$\mathrm{au}$ J. Antiproliferative effects of interleukin-4 on freshly isolated non-Hodgkin malignant B-lymphoma cells. Blood 1992; 79: 990-6.

35. Tepper RI, Pattengale PK, Leder P. Murine interleukin-4 displays potent anti-tumor activity in vivo. Cell 1989; 57: 503-12.

36. Toi M, Bicknell R, Harris. AL. Interleukin-4 inhibition of colon and breast carcinoma cell growth by interleukin-4. Cancer Res 1992; 52: $275-9$.

37. Gooch JL, Christy B, Yee D. STAT6 Mediates interleukin-4 growth inhibition in human breast cancer cells. Neoplasia 2002; 4: 324-31.

38. Tamm I, Cardinale I, Krueger J. Interleukin 6 decreases cell-cell association and increases motility of ductal breast carcinoma cells. J Exp Med 1989; 170: 1649-69.

39. MacMicking J, Qiao-wen X, Nathan C. Nitric oxide and macrophage function. Annu Rev Immunol 1997; 15: 323-50.

\section{Address for correspondence}

\section{Małgorzata Kowalczewska}

Department of Immunology

Faculty of Biology and Environment Protection

Nicolaus Copernicus University

Lwowska 1

87-100 Torun, Poland

e-mail: m kowalczewska@umk.pl

Submitted: 7.05.2014

Accepted: $\quad 6.08 .2014$ 